\title{
POLYCYCLIC AROMATIC HYDROCARBONS REMOVAL FROM PRODUCED WATER BY ELECTROCHEMICAL PROCESS OPTIMIZATION
}

\author{
USUWANIE WIELOPIERŚCIENIOWYCH WĘGLOWODORÓW \\ AROMATYCZNYCH PRZEZ OPTYMALIZACJĘ PROCESÓW \\ ELEKTROCHEMICZNYCH PODCZAS PRODUKCJI WODY
}

\begin{abstract}
Produced water is actually the wastewater separated from petroleum crude oil. Electrochemicaloxidation experiments was conducted for degradation of 16 priority polycyclic aromatic hydrocarbons $(P A H s)$ using DSA type $\mathrm{Ti} / \mathrm{IrO}_{2}$ anode. Laboratory scale batch reactor was used for degradation studies. To get the maximum $P A H s$ removal electrochemical process optimized on three independent variable current density, $\mathrm{pH}$ and electrolysis time. The response surface modelling (RSM) based on a Box-Behnken design was applied to get appropriate experimental design. $X_{1}, X_{2}$ and $X_{3}$ are the coded factors of independent variables such as the current density, $\mathrm{pH}$ and electrolysis time, respectively. Maximum removal was $95.29 \%$ at optimized conditions such as current density of $9 \mathrm{~mA} / \mathrm{cm}^{2}, \mathrm{pH} 3$ and electrolysis time $3.7 \mathrm{~h}$. Quadratic model was suggested best fit model. The results of the Analysis of Variances (ANOVA) for PAHs demonstrated that the model was highly significant.
\end{abstract}

Keywords: electrochemical treatment, $P A H s$, produced water, Box Bhenken Design, optimization

\section{Introduction}

Appropriate experimental design and suitable analysis of results is an important tool to evaluate an efficient environmental technology. Various mathematical models have important tools to develop appropriate experimental designs for optimizing variables for different wastewater treatment processes [1]. The majority of wastewater treatment processes are multi-variable and optimization through the classical method is inflexible, unreliable and time-consuming [2]. Response surface modelling (RSM) and Box Behnken Design are effective tools for optimization operational parameters in wastewater processes [3-5]. In our previous studies, RSM and Box Behken design has been successfully applied

\footnotetext{
${ }^{1}$ COMSATS Institute of Information Technology Abbottabad, University Road, 22060 Abbottabad, Pakistan, phone +92-333-50-44907, fax +92-992-383441, email: environment_green@yahoo.com

${ }^{2}$ Department of Civil and Environmental Engineering, Universiti Teknologi PETRONAS, Bandar Seri Iskandar 32610, Perak, Malaysia, email: hasnain_isa@yahoo.co.uk

*Corresponding author: humaajab@hotmail.com
} 
for optimization for $P A H s$ degradation from produced water [6, 7]. However, application of $\mathrm{RSM}$ for electrochemical treatment using $\mathrm{Ti} / \mathrm{IrO}_{2}$ anode has not yet reported.

Produced water (PW) is subsurface formation water coproduced during oil and gas production and has been described as the largest offshore discharge associated with fossil fuel extraction [8]. Over the economic life of a producing field, the volume of PW can be more than 10 times the volume of hydrocarbon produced [9]. In many onshore areas of the world, PW is usually injected into underground formations or simply discharged in wetlands and offshore areas [9]. Hydrocarbons that are found predominantly in PW include organic acids, polycyclic aromatic hydrocarbons $(P A H s)$ and phenols. These hydrocarbons are likely contributors to additional toxicity of PW [10]. Frost et al. [11] also identified heavy metals, radioactivity and aromatic hydrocarbons as potential causes of long-term effects. It is now generally accepted within the scientific community that the water-soluble fraction of $P A H s$ and phenols contribute most to the acute and chronic toxicity of produced water [11]. PAHs are therefore the principal focus of the further consideration in this paper of electrochemical treatment from produced water discharges.

Electrochemical oxidation has attracted wide attention as one of the environmentalfriendly technologies in wastewater treatment processes. Titanium anodes coated with $\mathrm{IrO}_{2}$ is the most widely used electro-catalyst for chlorine and oxygen evolution reaction in industrial electrochemistry for chlor-alkali electrolysis [12]. Titanium anode coated with noble metal oxides also exhibited a good effect on electrochemical oxidation of organic pollutants [13]. Electrochemical oxidation using $\mathrm{IrO}_{2}$ anode was found to be effective for degradation of tetracycline antibiotics in livestock wastewater [14], sulfide in oil wastewater [15] and ammonia in liquid waste [16]. Also in our previous study, PAHs were successfully removed in aqueous solution using $\mathrm{Ti} / \mathrm{IrO}_{2}$ anode [17].

In order to achieve a better implementation of the electrolysis, $\mathrm{IrO}_{2}$ coated titanium plates used as anodes were selected for this study. The response surface modelling (RSM) based on a Box-Behnken experimental design, was employed to study the effects of three independent variables (current density, initial $\mathrm{pH}$, and electrolysis time) for maximum PAHs removal from PW.

\section{Materials and methods}

\section{Experimental setup}

Batch experiments were conducted in an electrochemical cell consisted of an anode $\left(\mathrm{Ti} / \mathrm{IrO}_{2}\right)$ and a cathode (Ti plate) connected to DC power supply. Size of both anode and cathode plates was $(8 \mathrm{~cm} \times 1 \mathrm{~cm} \times 0.2 \mathrm{~cm})$ and distance between them is $2 \mathrm{~cm}$. $\mathrm{IrO}_{2}$ coated on titanium plates by thermal decomposition method described in previous studies [17]. All experiments were performed under galvanostatic conditions. Real produced water samples of volume $100 \mathrm{~cm}^{3}$ were used for all electrochemical experiments collected from offshore oil exploration site Malaysia. Electrochemical oxidation method was used for the degradation of $P A H s$ from produced water $[6,7,17,18]$. Initial concentration of total 16 priority $P A H \mathrm{~s}$ in PW was $160 \mu \mathrm{g} / \mathrm{dm}^{3}$.

\section{Experimental design for optimization}

The RSM based Box-Behnken design (BBD) was selected to find the optimum combination of independent variables $\left(X_{1}\right.$ : current density, $X_{2}$ : initial $\mathrm{pH}$, and $X_{3}$ : 
electrolysis time) for maximum $P A H s$ removal. The three independent variables were set at low, center and high levels, designated as $-1,0$, and +1 , respectively shown in Table 1 .

Coded and actual values

\begin{tabular}{|c|c|c|c|}
\hline \multirow{2}{*}{ Factors } & \multicolumn{3}{|c|}{$\begin{array}{c}\text { Coded and } \\
\text { actual values }\end{array}$} \\
\cline { 2 - 4 } & $\mathbf{- 1}$ & $\mathbf{0}$ & $\mathbf{+ 1}$ \\
\hline Current density; $X_{1}\left[\mathrm{~mA} / \mathrm{cm}^{2}\right]$ & 3.33 & 6.67 & 10 \\
\hline $\mathrm{pH} ; X_{2}[-]$ & 3 & 6 & 9 \\
\hline Time; $X_{3}[\mathrm{~h}]$ & 1 & 2.5 & 4 \\
\hline
\end{tabular}

Based on the combination of various levels of the input factors, 17 experimental runs, including 5 replicates of the center point, were generated by Design Expert software using the RSM/Box-Behnken method (Table 2). Five replicates at the center of the design were used to allow for estimation of a pure error sum of squares. A second-order polynomial model (Equation (1)), using Design Expert software, was fitted to the experimental data obtained according to the Box-Behnken design:

$$
Y=\beta_{0}+\sum_{j=1}^{k} \beta_{j}+\sum_{j=1}^{k} \beta_{j j} X_{j}^{2}+\sum \sum_{i<j} \beta_{i j} X_{i} X_{j}+e_{i}
$$

where $Y$ is the response, $X_{i}$ and $X_{j}$ are variables, $\beta_{0}$ is a constant coefficient, $\beta_{j}, \beta_{j j}$ and $\beta_{i j}$ are interaction coefficients of linear, quadratic and the second order terms respectively, $k$ is the number of studied factors and $e_{i}$ is the error. The significance of each coefficient in the equation was determined by $F$-test and $P$-values.

Experimental design and response for electrochemical removal of PAHs

Table 2

\begin{tabular}{|c|c|c|c|c|c|c|c|c|}
\hline \multirow{3}{*}{$\begin{array}{l}\text { Std. } \\
\text { Order }\end{array}$} & \multicolumn{3}{|c|}{ Independent variable } & \multirow{2}{*}{\multicolumn{2}{|c|}{$\begin{array}{c}\text { Response } \Sigma P A H s \text { removal } \\
{[\%]}\end{array}$}} & \multirow{2}{*}{\multicolumn{3}{|c|}{ Diagnostics case statistics }} \\
\hline & \multirow{2}{*}{$\begin{array}{c}X_{1} \\
\mathbf{C D}^{*} \\
{\left[\mathbf{m A} / \mathbf{c m}^{2}\right]}\end{array}$} & \multirow{2}{*}{$\begin{array}{c}X_{2} \\
\text { pH } \\
{[-]}\end{array}$} & \multirow{2}{*}{$\begin{array}{c}X_{3} \\
\text { Time } \\
{[\mathrm{h}]}\end{array}$} & & & & & \\
\hline & & & & $\begin{array}{l}\text { Actual } \\
\text { value }\end{array}$ & $\begin{array}{l}\text { Predicted } \\
\text { value }\end{array}$ & $\begin{array}{c}\text { Student } \\
\text { residual } \\
{[-]}\end{array}$ & $\begin{array}{c}\text { Cook's } \\
\text { distance } \\
{[-]}\end{array}$ & $\begin{array}{c}\text { Outlier } \\
t \\
{[-]}\end{array}$ \\
\hline 1 & 3.33 & 3 & 2.5 & 76.01 & 75.20 & -0.06 & 0.001 & -0.06 \\
\hline 2 & 10.00 & 3 & 2.5 & 95.00 & 95.09 & -0.30 & 0.03 & -0.28 \\
\hline 3 & 3.33 & 9 & 2.5 & 76.38 & 76.28 & 0.30 & 0.03 & 0.28 \\
\hline 4 & 10.00 & 9 & 2.5 & 97.36 & 98.66 & 0.06 & 0.001 & 0.06 \\
\hline 5 & 3.33 & 6 & 1.0 & 64.02 & 65.28 & 0.72 & 0.15 & 0.69 \\
\hline 6 & 10.00 & 6 & 1.0 & 84.00 & 83.87 & 0.95 & 0.27 & 0.95 \\
\hline 7 & 3.33 & 6 & 4.0 & 76.42 & 76.55 & -0.95 & 0.27 & -0.95 \\
\hline 8 & 10.00 & 6 & 4.0 & 96.70 & 96.92 & -0.72 & 0.15 & -0.69 \\
\hline 9 & 6.67 & 3 & 1.0 & 85.28 & 85.32 & -0.65 & 0.13 & -0.62 \\
\hline 10 & 6.67 & 9 & 1.0 & 87.56 & 86.38 & -1.02 & 0.31 & -1.02 \\
\hline 11 & 6.67 & 3 & 4.0 & 100.0 & 99.69 & 1.02 & 0.31 & 1.02 \\
\hline 12 & 6.67 & 9 & 4.0 & 100.0 & 99.80 & 0.65 & 0.13 & 0.62 \\
\hline 13 & 6.67 & 6 & 2.5 & 78.13 & 77.91 & 0.39 & 0.004 & 0.37 \\
\hline 14 & 6.67 & 6 & 2.5 & 76.85 & 77.91 & -1.93 & 0.09 & -2.61 \\
\hline 15 & 6.67 & 6 & 2.5 & 78.13 & 77.91 & 0.39 & 0.01 & 0.37 \\
\hline 16 & 6.67 & 6 & 2.5 & 78.80 & 77.91 & 1.61 & 0.06 & 1.88 \\
\hline 17 & 6.67 & 6 & 2.5 & 77.65 & 77.91 & -0.47 & 0.01 & -0.45 \\
\hline
\end{tabular}

*CD: current density 


\section{Analysis of variance (ANOVA)}

Analysis of variance (ANOVA) was used for data analyses and the interaction between the independent (process) variables and the dependent variable (response). The quality of fit of the polynomial model was expressed by $R^{2}$ and its statistical significance was examined by the $F$-test. Model terms were evaluated by the $P$-value (probability) with $95 \%$ confidence level. Three dimensional $(3 D)$ plots were obtained for PAHs degradation. The response values for the different experimental condition are shown in Table 2.

\section{Results and discussion}

Reaction conditions or independent variables (current density, $\mathrm{pH}$ and electrolysis time) were optimized for PAHs removal in PW during electrochemical oxidation process using $\mathrm{Ti} / \mathrm{IrO}_{2}$ anode. In order to determine the optimal conditions for the independent variables in percent removal of $\Sigma P A H s$ was chosen as experimental response to analyze the results for each anode. The independent variables $\left(X_{1}, X_{2}\right.$ and $\left.X_{3}\right)$ and response $Y(\Sigma P A H s$ removals [\%]) are shown in Table 2.

By applying multiple regression analysis on the experimental data, a second-order polynomial equation (1) was obtained to describe the correlation between the independent variables and the response.

After neglecting statistically non-significant terms relationship between response (PAHs removal) and the variables are expressed by the following second-order polynomial equation.

$$
Y\left(\mathrm{Ti} / \mathrm{IrO}_{2}\right)=+77.91+10.03 X_{1}+0.63 X_{2}+6.53 X_{3}-2.32 X_{1}^{2}+10.6 X_{2}^{2}+4.7 X_{3}^{2}
$$

\section{Analysis of variances}

Analysis of variances (ANOVA) for the second order polynomial equation is presented in Table 3.

ANOVA for Response Surface Quadratic Model with significant terms

\begin{tabular}{|c|c|c|c|c|c|}
\hline Source & $\begin{array}{c}\text { Sum of } \\
\text { squares }\end{array}$ & DF & $\begin{array}{c}\text { Mean } \\
\text { square }\end{array}$ & $\begin{array}{c}\boldsymbol{F} \\
\text { value }\end{array}$ & Prob $>\boldsymbol{F}$ \\
\hline Model & 1748 & 6 & 291 & 587 & $<0.0001$ \\
\hline $\boldsymbol{X}_{\mathbf{1}}$ & 804 & 1 & 804 & 1622 & $<0.0001$ \\
\hline $\boldsymbol{X}_{\mathbf{2}}$ & 3.14 & 1 & 3.14 & 6.33 & 0.0306 \\
\hline $\boldsymbol{X}_{\mathbf{3}}$ & 341 & 1 & 341 & 688 & $<0.0001$ \\
\hline $\boldsymbol{X}_{\mathbf{1}} \boldsymbol{X}_{\mathbf{2}}^{\mathbf{2}}$ & 22.7 & 1 & 22.7 & 45.9 & $<0.0001$ \\
\hline $\boldsymbol{X}_{\mathbf{3}}^{\mathbf{2}}$ & 473 & 1 & 473 & 954 & $<0.0001$ \\
\hline Residual & 92.9 & 1 & 92.92 & 187 & $<0.0001$ \\
\hline Lack of fit & 4.96 & 10 & 0.50 & & 0.54 \\
\hline Pure error & 2.88 & 6 & 0.48 & 0.92 & \\
\hline
\end{tabular}

Values of "Prob > F" less than 0.05 indicate model terms are significant. Values greater than 0.1000 indicate the model terms are not significant. For $\mathrm{Ti}^{\prime} / \mathrm{IrO}_{2}$ anode the $F$-value of "Lack of fit " $(0.05<0.92)$ implies that the lack of fit is not significant relative to the pure error. Non-significant lack of fit is good for the model. There is a $37.45 \%$ chance that a "Lack of fit $F$-value" this large could occur due to noise. $R$-Squared values 
and $p$ value $(p<0.0001)$ of the model also imply that the second-order polynomial model fitted experimental results well. Similarly $F$-value 587 of the model and low probability value indicated that the model is significant for $P A H s$ removal. The quadratic regression model was found to be highly significant.

The ANOVA of the model showed reliable confidence in estimation of PAHs removal. The square of correlation coefficient for response in model was computed as the coefficient of determination $\left(R^{2}\right)$. It showed high significant regression at $95 \%$ confidence level. Predicted $R$-Squared value is in reasonable agreement with the Adjusted $R$-Squared shown in Table 4 . High $R^{2}$ coefficients indicate a satisfactory adjustment of quadratic model to the experimental data.

Table 4

Model validation for PAHs removal using $\mathrm{Ti} / \mathrm{IrO}_{2}$ anode

\begin{tabular}{|c|c|c|c|c|c|c|}
\hline $\boldsymbol{R}^{2}$ & Adjusted $\boldsymbol{R}^{\mathbf{2}}$ & Predicted $\boldsymbol{R}^{\mathbf{2}}$ & Std. dev. & Mean & C.V. & PRESS \\
\hline 0.998 & 0.997 & 0.994 & 0.59 & 84.02 & 0.75 & 14.76 \\
\hline
\end{tabular}

PRESS refres to Predicted Residual Sum of Squares. "Adeq Precision" $(A P)$ measures the signal to noise ratio Desired value of $A P$ should be 4 or more. $A P$ values shown in table for each model was found higher than 4 which indicates an adequate signal. $A P$ values higher than 4 indicates that the predicted model can be used to navigate the design space defined by the $B B D$. Simultaniously low values of coefficient of variation $(C V)$ indicated good precision and reliablity of the experiments.

\section{Interaction between variables}

From model, the significant terms are $X_{1}, X_{2}, X_{3}, X_{1}^{2}, X_{2}^{2}$, and $X_{3}^{2} . X_{1} X_{2}, X_{1} X_{3}$ and $X_{1} X_{3}$ interactions are not exist in the model because current density $\left(X_{1}\right)$ and electrolysis time $\left(X_{3}\right)$ has main effect on response variable.

In Figure 1a, PAHs removal increases by increasing current density at all initial $\mathrm{pH}$ values keeping electrolysis time $X_{3}$ constant at $2.5 \mathrm{~h}$. Also in Figure 1c, higher PAHs removal has found by increasing electrolysis time at all $\mathrm{pH}$ value by keeping current density constant at $\left(6.67 \mathrm{~mA} / \mathrm{cm}^{2}\right)$. During evolution of chlorine, indirect electrochemical oxidation of organic compounds takes place through chlorine/hypochlorite; however, the production rate of chlorine/hypochlorite did not affected by initial $\mathrm{pH}$ conditions [19].

\section{Adequacy of model}

To check that selected model provides adequate approximation of real system or not some diagnostic data analyses were performed based on actual and predicted values. Actual values were experimental values while the predicted values were calculated from the model (Eq. (2)). Figure 2 shows normal distribution of actual and predicted response for total $P A H s$ removal for the model. While Figure $2 \mathrm{~b}$ shows the studentized residuals, the differences between actual and predicted response for $P A H s$ removal. The figure obtained by ploting studentized residauls versus normal percentage of probability experiments. In Figure 2a, actual and predicted values are closer to each other. All the data points in plots lies on straight line which indicates that data is fairly distributed. It is clear from Figure $2 b$ the residuals are between \pm 2 . It also confirmed that selected model provide adequate approximation of real system. 

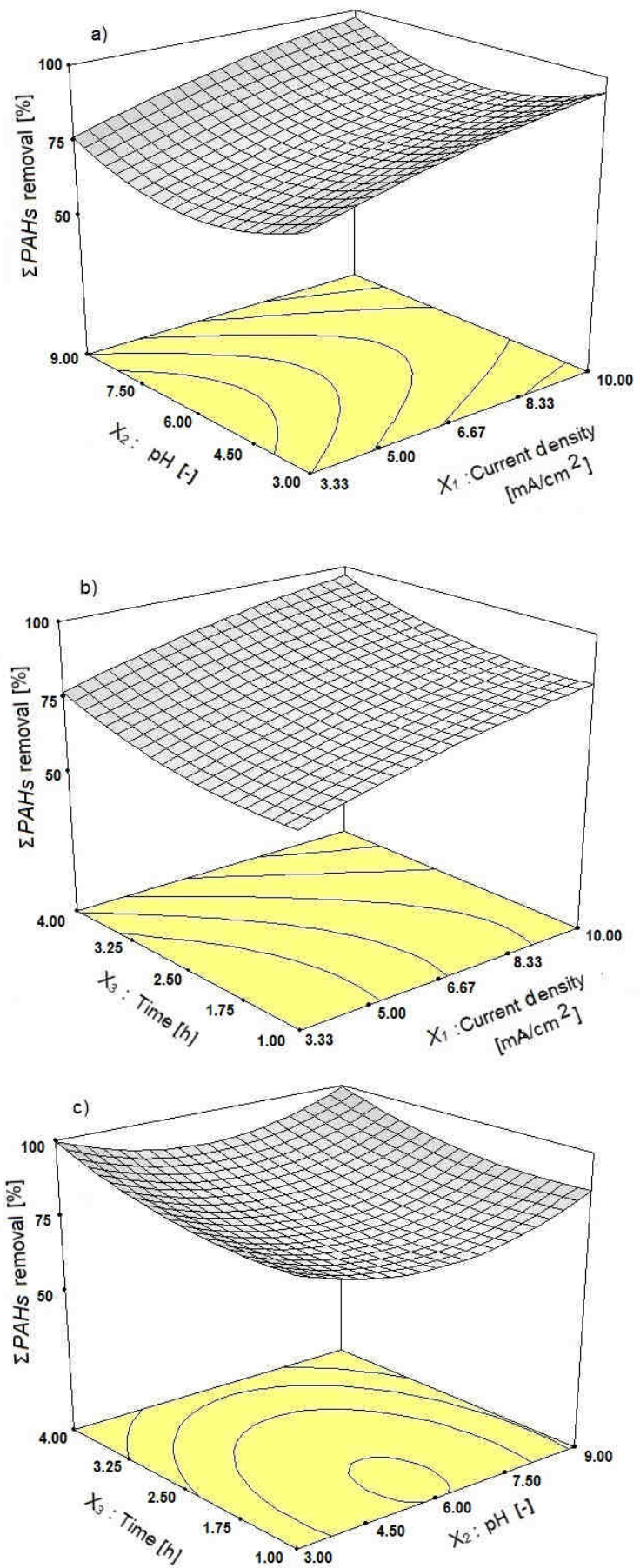

Fig 1. 3D surface plot showing interactions between independent variables: a) $X_{1} X_{2}$, b) $X_{1} X_{3}$, c) $X_{2} X_{3}$ 

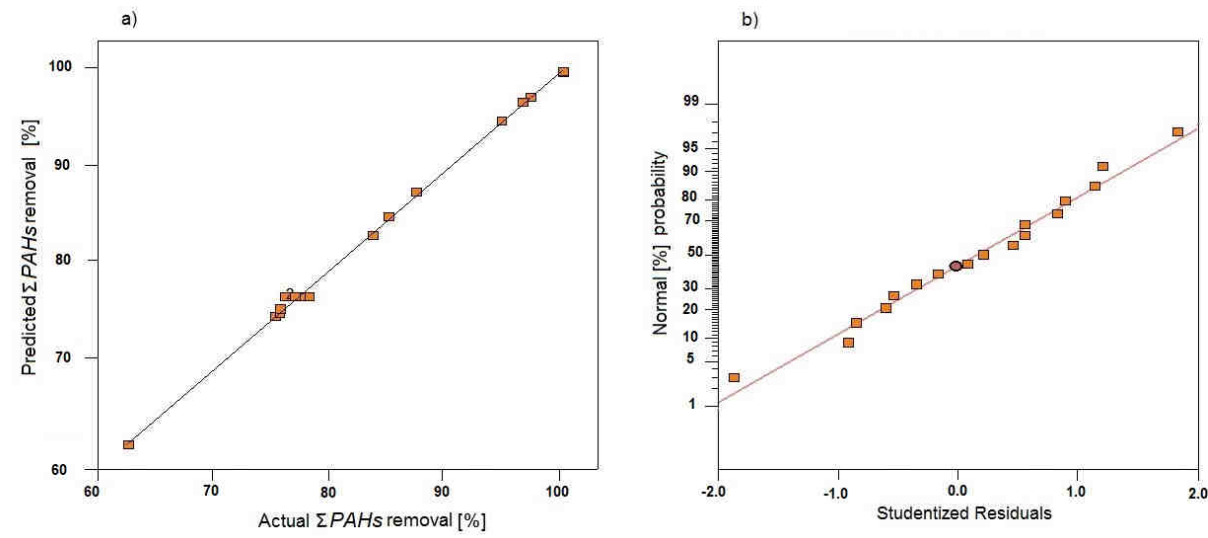

Fig. 2. Plot of a) predicted response vs actual response and b) normal plot of studentized residuals

\section{Optimized results}

After analyzing the response optimum values were determine using Design Expert Software, by applying numerical model under the option Optimization. All the parameters were taken in range (for CD lower limit $3.33 \mathrm{~mA} / \mathrm{cm}^{2}$ and upper limit $10 \mathrm{~mA} / \mathrm{cm}^{2}$ ), (for initial $\mathrm{pH}$ lower limit 3 and upper limit 9) and (electrolysis time lower limit $1 \mathrm{~h}$ and upper limit $4 \mathrm{~h}$ ) for maximum $P A H$ s removal. The optimized condition obtained at current density of $9 \mathrm{~mA} / \mathrm{cm}^{2}$, pH 3 and electrolysis time $3.7 \mathrm{~h}$ shows maximum removal of $95.29 \%$. Good agreement between the predicted and experimental results (95.86) verified the validity of the model and existence of an optimal point.

\section{Conclusion}

Optimization plays a main role in wastewater treatment applications since the best treatment performance mainly corresponds to an optimum point or best range of operational parameter values. Hence, RSM based BBD experimnetal design is an efficient design for optimization of PAHs degradation from $\mathrm{PW}$ using $\mathrm{Ti} / \mathrm{IrO}_{2}$ anode. Current experimental design can be used for parameters optimization for oil industry wastewater treatment.

\section{References}

[1] Castillo A, Cheali P, Gómez V, Comas J, Poch M, Sin G. An integrated knowledge-based and optimization tool for the sustainable selection of wastewater treatment process concepts. Environ Model Softw. 2016;84:177-192. DOI: 10.1016/j.envsoft.2016.06.019.

[2] Arulmathi P, Elangovan G, Begum AF. Optimization of electrochemical treatment process conditions for distillery effluent using response surface methodology. Scientific World J. 2015;1-9. DOI: $10.1155 / 2015 / 581463$.

[3] GilPavas E, Dobrosz-Gómez I, Gómez-García MÁ. Electrochemical degradation of Acid Yellow 23 by anodic oxidation-optimization of operating parameters. J Environ Eng. 2016;142 p.04016052. DOI: 10.1061/(ASCE)EE.1943-7870.0001127.

[4] Tolian G, Jafari SA. Zarei S. Optimization of biosorption of nickel(II) and cadmium(II) by indigenous seaweed Enteromorpha using response surface methodology. Water Qual Res J Can. 2015;50(2):109-122. DOI: 10.2166 /wqrjc.2015.007. 
[5] Fakhri A. Investigation of mercury(II) adsorption from aqueous solution onto copper oxide nanoparticles: optimization using response surface methodology. Process Saf Environ Prot. 2015;93:1-8. DOI: 10.1016/j.psep.2014.06.003.

[6] Yaqub A, Isa MH, Ajab H. Electrochemical degradation of polycyclic aromatic hydrocarbons in synthetic solution and produced water using a Ti/SnO${ }_{2}-\mathrm{Sb}_{2} \mathrm{O}_{5}-\mathrm{RuO}_{2}$ anode. J Environ Eng. 2015;141(4):p.04014074. DOI: 10.1061/(ASCE)EE.1943-7870.0000900.

[7] Yaqub A, Isa MH, Kutty SRM, Ajab H. Electrochemical degradation of PAHs in produced water using $\mathrm{Ti} / \mathrm{Sb}_{2} \mathrm{O}_{5}-\mathrm{SnO}_{2}-\mathrm{IrO}_{2}$ anode. Electrochemistry. 2014;82(11):979-984. DOI: 10.5796/electrochemistry.82.979.

[8] Balaam JL, Chan-Man Y, Roberts PH, Thomas KV. Identification of non-regulated pollutants in North Sea-produced water discharges. Environ Toxicol Chem. 2009;28(6):1159-1167. DOI: 10.1897/08-488.1.

[9] Stephenson MT. Components of produced water: A compilation of industry studies. Soc Petrol Eng J. 1992;548-603. DOI: 10.2118/23313-PA.

[10] An C, Huang G, Yao Y, Zhao S. Emerging usage of electrocoagulation technology for oil removal from wastewater: A review. Sci Total Environ. 2017;579:537-556. DOI: 10.1016/j.scitotenv.2016.11.062.

[11] Frost TK, Johnsen S, Utvik TIR. Produced water discharges to the North Sea, fate and effects in the water column. OLF (Oljeindustriens Landsforening); December 1998. http://www.olf.no/static en/rapporter/producedwater/.

[12] Panić VV, Dekanski AB, Mišković-Stanković VB, Milonjić SK, Nikolić BŽ. Differences in the electrochemical behavior of ruthenium and iridium oxide in electrocatalytic coatings of activated titanium anodes prepared by the sol-gel procedure. J Serb Chem Soc. 2010;75(10):1413-1420. DOI: 10.1039/B921582D.

[13] Kristóf J, Mihály J, Daolio S, De-Battisti A, Nanni L, Piccirillo C. Hydrolytic reactions in hydrated iridium chloride coatings. J Electroanal Chem. 1997;434:99-104. DOI: 10.1016/S0022-0728(96)05068-1.

[14] Miyata M, Ihara I, Yoshid G, Toyod K, Umetsu K. Electrochemical oxidation of tetracycline antibiotics using a $\mathrm{Ti} / \mathrm{IrO}_{2}$ anode for wastewater treatment of animal husbandry. Water Sci Technol. 2011;63(3):456-461. DOI: 10.2166/wst.2011.243.

[15] Wang Y, Li M, Feng C, Zhang Z. Electrochemical oxidation of sulfide in oil wastewater using Ti//rO anode. Environ Prog Sust Energy. 2012;31(4):500-506. DOI 10.1002/ep.10565.

[16] Liu Y, Li L, Goel R. Kinetic study of electrolytic ammonia removal using $\mathrm{Ti} / \mathrm{IrO}_{2}$ as anode under different experimental conditions. J Hazard Mater. 2009;167(1):959-965. DOI: 10.1016/j.jhazmat.2009.01.082.

[17] Yaqub A, Isa MH, Kutty SRM, Ajab H. Surface characteristics of $\mathrm{Ti} / \mathrm{IrO}_{2}$ anode material and its electrocatalytic properties for polycyclic aromatic hydrocarbons (PAHs) degradation in aqueous solution. J New Mater Electrochem Sys. 2014;17(1):39-44. http://www.groupes.polymtl.ca/jnmes/modules/ journal/index.php/content0827.html.

[18] Yaqub A, Isa MH, Ajab H, Junaid M. Electrochemical degradation of petroleum hydrocarbons (PAHS) from synthetic aqueous solutions. Petro Chem. 2017;57(5):457-465. DOI: 10.1134/S0965544117050140.

[19] Vijayaraghavan K, Ramanujam T, Balasubramanian N. In situ hypochlorous acid generation for the treatment of textile wastewater. Color Technol. 2001;117:49-53. DOI: 10.1111/j.1478-4408.2001.tb00335.x. 